\title{
The Use of Drones in the Spatial Social Sciences
}

\author{
Ola Hall ${ }^{1}$ and Ibrahim Wahab ${ }^{1, *}$ \\ ${ }^{1}$ Department of Human and Economic Geography, Lund University \\ e-mail: ola.hall@keg.lu.se and Ibrahim.wahab@keg.lu.se \\ * Corresponding author
}

\begin{abstract}
Drones are increasingly becoming a ubiquitous feature of society. They are being used for a multiplicity of applications for military, leisure, economic, and academic purposes. Their application in the latter, especially as social science research tools has seen a sharp uptake in the last decade. This has been possible due, largely, to significant developments in computerization and miniaturization which have culminated in safer, cheaper, lighter, and thus more accessible drones for social scientists. Despite their increasingly widespread use, there has not been an adequate reflection on their use in the spatial social sciences. There is need a deeper reflection on their application in these fields of study. Should the drone even be considered a tool in the toolbox of the social scientist? In which fields is it most relevant? Should it be taught as a course in the universities much in the same way that geographic information system (GIS) became mainstream in geography? What are the ethical implications of its application in the spatial social science? This paper is a brief reflection on these questions. We contend that drones are a neutral tool which can be good and evil. They have actual and potential wide applications in academia but can be a tool through which breaches in ethics can be occasioned given their unique abilities to capture data from vantage perspectives. Researchers therefore need to be circumspect in how they deploy this powerful tool which is increasingly becoming mainstream in the social sciences.
\end{abstract}

Keywords: Drones, legislation, ethics, spatial social sciences 


\section{Introduction}

The term drone, originally referring to the male bee ${ }^{1}$, is the everyday name for autonomous aircraft. Drones tend to evoke memories of warfare as they were first flown during the First World War during which they were often launched using a catapult. Since then, they have been used as tools for reconnaissance, for deploying propaganda leaflets, decoys for missile launches or even as actual combat platforms in multiple war theaters. In more recent times, drones have become household names for their non-military uses. There have been several attempts to delink them from their militaristic past. These efforts include popularizing more civilian-leaning names for these systems. To this end, common monikers include unmanned aerial vehicles (UAV), remotely-piloted aircraft (RPA) or vehicle (RPV), unmanned aerial system (UAS), or the recent, gender-neutral form, uncrewed aerial vehicle (also UAV). Notwithstanding these efforts, the traditional terminology has however stuck and so even now, major industry players offer 'drones' and 'mini-drones' as flagship products.

Within the last decade, drones have become a much more common feature of life. This is largely attributable to the fact that they have become relatively cheaper to manufacture, compared to just two decades ago. This is mainly down to significant technological advances in computerization and miniaturization. The former has exponentially increased the processing power of computers and the ability of process data from drones even on low-cost laptops while the latter has dramatically reduced cost of production with less expensive components such as carbon fiber. Increasing civilian use of drones has also accompanied improvements in features aimed at augmenting safety. These features include obstacle-avoidance and Vertical take-off and land (VTOL) systems. The latter allows take-off and landing of the drone system even in challenging terrains while the former help prevent mid-flight collision with other aircraft, trees, or buildings.

The application of drones is expanding just as their use in multiple facets of life is growing. In addition to being used as leisure tools, drones have several applications in weather forecasting, search and rescue operations, disaster management, crowd control, delivery of vaccines and blood for transfusion, among others. One area that has also begun seeing the increased application of drones in the last decade is academia. In this regard, both the physical as well as the social sciences have found it a useful tool. Some disciplines, by virtue of the subject matter and focus, find the incorporation of drones into their research systems easier than others. For instance, in the physical sciences, the subject matter is often physical, and the unit of analysis could be rocks, stars, plants, or animals. Studying such using drones is easier and more straightforward than the social sciences which subject matter is society itself and the unit of analysis is often humans. The latter are more complex units of study because they are sentient, conscious, and can modify their activities under study. Related to this are ethical dilemmas as well as questions about objectivity when we study, our as well as other, societies. Given our biases, both declared and undeclared, as well as recognized and unrecognized, there is often the need for greater reflexivity is social science studies, especially in collecting data.

Generally, social scientists employ a range of tools and methods to collect data for their studies. These methods range from experiments, surveys, interviews, focus group discussions (FGDs), participant observations, life histories, and documentation analysis, among others. While each of these methods have

\footnotetext{
${ }^{1}$ Drones were probably named after the honeybee due to the parallels between the two in terms of life cycles; akin to the first military drones, the singular purpose of the honeybee drone is to fertilize a queen bee during a mating flight and die off.
} 
their strengths and weaknesses, their appropriateness depends on the context of studies. Some social science disciplines are more inclined to relying on visual methodologies than others. The social science disciplines of anthropology, archaeology, economics, geography, history, and sociology have found drones as useful research tools. Of these, anthropology and geography are unique in their reliance on the visual and visual images to construct their knowledge (Rose, 2003). Given drones' advantage of providing access to the three-dimensional space (Birtchnell, 2017), and geography's preoccupation as a spatial science, drones have found a much more accepting audience among geographers, compared to other social scientists. Even within geography, not only are drones helping to bridge the gap but is also offering new opportunities for collaborative research between human and physical geographers given that these two subdisciplines often approach the application of drones differently (Garrett \& Anderson, 2018).

In this conceptual paper, we aim to discuss the use of drones as social science research tools. In this vein, we focus the discussion on three main themes: teaching their use as courses in universities, legislations governing their use across countries and the ethical and political hurdles that need reflection in their application, particularly in the social sciences. While the civilian use of drones for surveillance and policing to fight crime is generally socially acceptable (West \& Bowman, 2016), there is often a certain level of uneasiness and strong push back against a continuous, universal, and an all-seeing flying big brother in the sky (Neocleous, 2013), given the potential for abuse and concerns for privacy. These reflections are critical as drones continue to become mainstream tools in the toolbox of the social scientist.

\section{Drones as social science research tools}

The application of drones in the social sciences as data collection tools comes on the back of the use of satellite imagery in the same endeavours. The latter can be traced to the mid-1990s when the National Aeronautics and Space Administration (NASA) approached the research community to realize the potential of satellite imagery to specifically address questions which social scientists are preoccupied with. Notwithstanding the high expectations from this collaboration expressed in People and Pixels: Linking Remote Sensing and Social Science (Livermore et al., 1998), the results have been meagre, and their added value questioned. Much of the difficulties that limited the success of using remotely sensed satellite imagery - coarse resolution of most readily available datasets, the challenge with cloud cover, particularly in the tropics, and limitations relating to temporal resolutions - persist till date. This is despite the significant strides that have been made in this area in the last two decades. It is on the back of these challenges that other platforms have been proposed as alternatives to satellites as remote sensing platforms for collecting critical data about the earth's surface. As the third generation remote sensing platform - with piloted aircraft as first generation and earth-orbiting satellites as second generation (Simic Milas et al., 2018) - drones are proving much more ubiquitous in terms of its applications in scientific research.

Drones and drone imagery position the researcher and the objects of interest closer together, both physically as well as conceptually. Compared to satellite imagery, the low flying altitude, small area coverage, and the detailed visuals that drones offer create a familiar perspective, closely related to traditional field work. Unlike, satellite imagery, drone imagery is usually ready to be used as a map base or in photo elicitation interviews (Glaw et al., 2017; Harper, 2002; Wahab et al., 2020). They could also be processed, classified, and analyzed in a more conventional remote sensing way (Hall et al., 2018; Wahab et al., 2018). Thus, drone imagery can either be used on its merit or to improve the quality of data that other more conventional methods of data collection produce. For instance, van Auken et al. (2010) enumerate the advantages that photo-elicitation interviews have over more traditional social science research tools such as the provision of tangible stimuli for more effectively tapping into informants' tacit, and often unconscious knowledge, 
consumption of representations, images and metaphors, and thus leading to the production of different and richer information than other techniques, while also helping to reduce differences in power, class and knowledge between researcher and researched. In the developing world which is invariably the 'data-poor' world, drone imagery has proven an indispensable tool for research.

Geographical applications of drones are perhaps more widespread than in other fields. In the sub-field of physical geography, drones have gained wide acceptance for studying rock weathering (Mol \& Clarke, 2019; Verma \& Bourke, 2019), for river bed monitoring (Piégay et al., 2020; Vázquez-Tarrío et al., 2017) and restoration (Marteau et al., 2017). In this area, studies have progressed beyond proof-of-concepts to real world applications for geomorphological change detection and mapping, vegetation mapping, habitat classification and sediment transport path delineation (Carrivick \& Smith, 2019). Further downstream, Callow et al. (2018) used a drone to generate high-accuracy, centimeter-resolution digital topographic models which offer insights into the likely consequences of inundation and the dynamics that control lowgradient sedimentary landforms. It is not surprising that geography in general, and the subdiscipline of physical geography, in particular were always going to be more accepting of drones due mainly to the their 'vertical' and 'visual' character. The proliferation of drones as research tools however avails further opportunities for intra-discipline collaboration between physical and human geographers (Garrett \& Anderson, 2018).

In agricultural geography, drone applications include mapping crop condition and yield estimation (Adewopo et al., 2020; Wahab et al., 2018; Yonah et al., 2018), crop classification (Hall et al., 2018), seedling emergence assessment, crop damage assessment, weed detection and mapping (van der Merwe et al., 2020). In general terms, drones have been heralded as the right tools for making agriculture smart, especially in Sub-Saharan Africa where the application of the first- and second-generation remote sensing platforms have met with largely limited success. This limited success is due to such factors as costs of acquisitions, cloud cover, low spatial and temporal resolutions vis-à-vis the predominance of small farms in SSA. Multiple reviews such as Daponte et al. (2019); Puri et al. (2017) have chronicled the use of drones in the field of smart agriculture. Iost Filho et al. (2019) more specifically reviewed the application of drones as noninvasive crop monitoring system in precision pest management. Three main niches exist in this subfield for drone application: (1) scouting for problems, (2) monitoring crops to prevent/reduce losses, and (3) planning crop management operations (Hunt \& Daughtry, 2018). Similarly, Barbedo (2019) offers are comprehensive and critical review of the use drone in this area, chronicling the major milestones, the main research gaps and possibilities for future research with the application of even newer techniques of machine learning on drone images.

This is however not to assert that drones are not already useful research tools in the other subdisciplines of human geography. In tourism studies, for example, the usefulness of drones continues to grow. Here, drones are being used for monitoring and patrolling tourism activities for safety and security as well as for virtual tourism systems (Song \& Ko, 2017). For virtual tourism, drones serve as destination marketing tools to produce large amounts of visually appealing footages of various destinations (Stankov et al., 2019). On the part of tourism service providers, major considerations regarding economic viability and operational feasibility need to be addressed in order to efficiently deploy drones in the tourism sector (Ko \& Song, 2021). While tourists tend to have a better appreciation of the potential uses of drones compared to managers of tourist centers, there is need to set boundaries of what is acceptable (Hay, 2016). Beyond tourism studies, drones are finding applications as research tools in cultural geography, health geography, rural geography, transportation geography, and urban geography, among others.

In the area of environmental geography, for instance, community drones for natural resource management and conservation is a strongly growing area (Burke et al., 2019; Rush et al., 2018; Valle \& Scarton, 2020; 
Vargas-Ramírez \& Paneque-Gálvez, 2019). Much of the work in this area emanate from Latin America and, to a lesser extent, South-East Asia. Drone applications are most useful on cases where the study locations are usually difficult to physically access. A number of reviews such as Paneque-Gálvez et al. (2017), Canal and Negro (2018), Beaver et al. (2020), have emerged in this area that point to current and potential significant contributions that drones can be put to in natural resource management. Cummings et al. (2017) go a step further to demonstrate how drones can be adapted in indigenous peoples' dominated settings in a collective and concerted manner. Following such a collaborative approach can help build mutually beneficial relationships as it respects indigenous culture and customary norms which in turn augurs well for a sustainable monitoring and protection of natural ecosystems. Vargas-Ramírez and Paneque-Gálvez (2019) provide a broad overview of this growing field of community drones, finding that local knowledge is often neglected or undervalued, and emphasizing the need to recognize indigenous peoples' territorial rights. Done well, participatory action mapping (PAM) using drones can be useful for bolstering political and legal claims of indigenous communities to counteract land grabs by foreign entities (Radjawali \& Pye, 2017; Radjawali et al., 2017). Conversely, unintended negative consequences of PAM include fragmentation and conflicts among indigenous communities and the facilitation of land acquisitions, either by the state or corporations, following legal recognitions (Dewi, 2016). There is also the need for researchers engaged in PAM to pay attention to the digital divide that often exists between them and indigenous communities, a situation which is symptomatic of broader socioeconomic and political inequalities which are largely legacies of colonialism (Smith et al., 2017).

In archaeology, drones are becoming increasingly useful in studying previously unrecognizable features. For example, Cucchiaro et al. (2020) demonstrate that orthomosaics from drones provided an accurate and high level of detail of the terrace landscape, the archaeological features and sediment stratigraphy along an excavation trench previously unobserved. Similarly, Brown et al. (2021) show the beneficial use of drones to map multi-faceted terraces under intensification and diversification. In landscape archaeology, Stek (2016) demonstrates the utility of drones for detecting previously undocumented subsurface archaeological artifacts in mountainous, Mediterranean landscapes. Campana (2017) provides an excellent review of the application of drones in archaeology and delineates five main areas of application: exploratory aerial survey, survey of archaeological sites and landscapes, three-dimensional (3D) documentation of excavations, 3D survey of monuments and historic buildings, and archaeological survey of woodland areas. Just like in tourism studies, the application of drones which makes hitherto unobservable sites accessible and requires some safeguards to ensure that aerial photos do not contribute to looting and destruction of heritage sites (Jorz, 2019).

Different fields incorporate drones into the fieldwork and studies to varying extents. The broad of field of geography is however relatively more predisposed to employing drones compared to other fields because it uses the full sweep of quantitative and qualitative methods and places greater emphasis on fieldwork and mapping. This is underpinned by its special focus on spatial analysis and areal differentiation. Perhaps, through more widespread teaching of drones as a stand-alone course at universities, other fields might come to realize their value and how they can be adopted and utilized to suit discipline's peculiar needs.

\section{Teaching drones in higher education}

In this era of rapid data collection, drones have emerged as a well-established emerging geospatial technology, for collecting and analysing primary remote sensing data. In terms of importance, they are poised to be as revolutionary for geography in the same order of magnitude as geographic information systems were a couple of decades ago. In the foreword to the book Spatially Integrated Social Science 
(2004), Norman Bradburn succinctly states not just the potential but also the impact that geographic information system has had on the spatial sciences: "The advent of geographic information systems (GIS) has enabled an explosion of interest in and ability to study the spatial patterns of behaviour. GIS not only makes it possible to store in digital form vast amounts of spatial data, it makes possible statistical analysis, modelling, and visual display of geographical data... We are at the dawn of a revolution in a spatially oriented social science". We hold similar views on the role that drones can play in the spatial social sciences. Indeed, the use of GIS twenty years ago and drones now in the spatial social sciences bear striking parallels not only because of their identical origins but also given that drones are the latest technological tools for collecting and viewing space. They offer a method for collecting and accumulating data from strategic viewpoints (Birtchnell \& Gibson, 2015) and there are many social science disciplines that can benefit from this vantage perspective. Given its ubiquity in society and increasing application even in the social sciences, there is increasingly obvious need for having a dedicated course on drones in researchoriented universities.

Effective teaching of the principles and applications in a field as dynamic geographic information systems and technology in higher education is usually challenging (Mathews \& Wikle, 2019) and drones is no exception in this. This is partly down to the constant change that this niche of study is subject to. Effective teaching of drones in institutions of higher learning needs to overcome two fundamental issues: teachers need to adopt and adapt new paradigms and tools while keeping up to date with newer trends in the field and yet, also develop effective methods for transferring the new competences to students. Teaching of drones, especially when it encompasses image acquisition, data processing and interpretation, has been shown to significantly enhance students' data processing skills while enhancing their competences in handling data quality issues (Williams et al., 2017). Consequently, this field is usually at the cutting edge of teaching and learning approaches, with traditional approaches giving way to more modern methods.

In recent times, more traditional approaches such as pen-and-paper in lectures and laboratory exercises are giving way to more active learning strategies such as 'flipped classrooms' (Mathews \& Wikle, 2019). Such participatory and collaborative approaches lay good foundations among students for participatory action research and popular education approaches which ensure community participation and cultural appropriateness of the methods that are employed in data collection using drones (Vargas-Ramírez \& Paneque-Gálvez, 2019). This, however, often require further training not only on the part of students but instructors as well. On the part of instructors, there is often the need to allocate extended periods of preparation for classes to keep abreast with software updates as well as new trends and developments in the general field of geographic information science and technology (Mathews \& Wikle, 2019) and the specific field of image analysis, especially using artificial intelligence techniques of machine learning and deep learning using big data. Holloway et al. (2021) further posit that, with regards to new technologies, such new approaches foster teamwork, peer-to-peer learning, and positively reinforce the uptake of such technologies in fieldwork.

Already, some institutions are setting the pace in teaching drones both at undergraduate and advanced levels. In the United States, the Drone Journalism programmes at the Universities of Missouri and Nebraska-Lincoln are pacesetters in drone studies. In such programmes, students are taught not only the technical skill of flying a drone mounted with cameras to collect aerial data, but also the ethics of collecting data on people in public places and the legal, safety and regulatory frameworks across various jurisdictions and areas as well as the analysis of aerial data (Birtchnell \& Gibson, 2015). For instance, flying regulations are different for within a 2-km radius of an airport from those for a rural area (Garrett \& Anderson, 2018). For safety reasons, special rules also apply to flying altitudes, with about 100 metres often considered safe altitudes. Elsewhere on continental Europe, the Oslo School of Architecture and Design is also considered 
an early pioneer in the teaching of drones as a course (Morrison et al., 2013). Other research-oriented universities should be following these early innovators in this endeavour. The main challenge for instructors is to cover the three fundamentals of remote sensing - planning, data collections, and image analysis while minimising logistical and practical issues associated with the actual flights (Hodgson \& Piovan, 2021). A further hurdle in this is securing the necessary certifications to be able to train pilots within the existing legislation framework.

Those institutions that do not have the infrastructure or which are in jurisdictions where private drone use, even for academic purposes, is significantly restricted, could liaise with already established pilot schools to train students on the technical aspects of flying while they focus on the theoretical, philosophical, ethical, and methodological aspects of drone use in the social sciences. The onus falls on geographers, both physical and human geographers, to actively engage with this technology and lead cross-disciplinary discussions on not only the processing of drone data but also the ethical implications of its use. Collaborating with specialized flight training schools thus helps to overcome barriers relating to privacy, laws, and licensing.

\section{Legislations on drone use across countries}

Much like other technological innovations, regulations for drones have been playing catch-up with the proliferation and use of the devices (West et al., 2019). Different countries have reached different regulation development stages for drones, with most countries, especially in Africa, having developed their national guidelines within the last half decade. Even among OECD countries, there is substantial heterogeneity in national legal frameworks on drone regulation (Tsiamis et al., 2019). Regulations on the use of drones are necessary due to the potential for breaching privacy, data protection, and public peace (Ayamga et al., 2021). Regulations relating to licensing and operations, thus significantly vary across countries even though a substantial proportion - 40 to $85 \%$ - of the provisions of legislations governing drone usage is often sourced from the manual of the International Civil Aviation Organization (Ayamga et al., 2021). Even where regulations have been harmonized, as is the case with the European Union new regulation which came into force in January 2021, stakeholders often find them cumbersome due to administrative and bureaucratic complexities in their interpretations (Alamouri et al., 2021). There are a few data repositories for information on drone regulations worldwide. A useful portal for the most up-to-date information on drone regulations for various jurisdictions can be found at: https://www.droneregulations.info/index.html Here, one can access the specific website of respective national authorities responsible for licensing and issuing guidelines and regulations for drone pilots. The portal thus serves as a one-stop-shop for the most updated laws on the use of drones on each country.

A major challenge relating to the regulations is restrictions they tend to come with. This is particularly true when regulatory agencies fear lives could be at risk. In such circumstances, there is a tendency for broad restrictions which limit adoption and use of drones even for academic research (Alamouri et al., 2021; Ayamga et al., 2021). These barriers are sometimes purely financial. For example, Kenya Airways has an entry-cost of about USD 1,600 for a month-long course to obtain a license to fly a drone in Kenya (Otieno, 2021). This charge excludes other charges such as the cost of medical examination. The initial license issuance costs some USD 720 and this is renewable at a fee of about USD 460 (KCAA, 2020). This area is however in constant flux. Countries are regularly reviewing regulations to improve the ease of use of drones in their jurisdictions. In the United States which is a pioneer in this area, for example, drone operators are no longer required to pass a medical examination nor have a liability insurance. Drone pilots are only required to pass an aeronautical knowledge test rather than acquire any form of pilots' license. 
Other portals exist to check drone operations and report incidents involving drones. The most popular one being the drone incidents and intelligence system https://www.drone-detectives.com/. The primary purpose of this portal is to safeguard public safety by allowing private individuals to report dangerous drone activities and filing accidents involving drones. Some of the details one can report include date and time of incident, the type/model of drone involved, and the altitude at which the drone was flying as well as the specifics of the incident such as a proximity to airport airspace or military installations. Such reports are useful for regulatory institutions in their monitoring activities. Apart from showing incidents involving drones, drone detectives are also useful in noting the various No Fly Zones in all countries. These are usually over military installations, airport airspace and public spaces such as parks and stadia. Thus, while the fundamental role of these national regulations relating drone use is to ensure public safety and security, some of the rules will have to be relaxed as drone features such as obstacle sensing and avoidance systems improve. Legislations on drones often have three main aims: (1) regulate the use of airspaces; (2) impose operational limitations; and (3) outline administrative processes for permissions, licenses and authorizations (Ayamga et al., 2021). The overall aim is therefore safety and security. The enactment of such rules is fundamental for further tapping into the potential benefits that drones come with in the various fields.

Several studies and reviews have been carried in this area of regulations governing drone use and the implications of these on the industry. In the last year alone, Alamouri et al. (2021) provide an overview of recent updates on drone regulations in the European Union area and show how regulations can help and hinder the use of the technology. Similarly, Hodgson and Sella-Villa (2021) provide a review of the regulatory regimes in the United States, with particular reference to its application for academic research. They further highlight the complexities relating to restrictions on flying over critical infrastructure such as security installations when the locations of such facilities are classified for security reasons as well as recommendations on how researchers can obtain exemptions from often sweeping restrictions. In the African context, Ayamga et al. (2021) provide a review of the challenges that regulations pose for drone adoption and application, with specific focus on the field of agriculture. They argue that while the political commitment may be present in most Sub-Saharan African countries, regulations are often hampered by inadequate capacity to develop and enforce drone regulations.

\section{Ethical and safety considerations}

In terms of safety, drones are generally considered relatively safer than piloted aircraft for two main reasons; first, they are not piloted and so there is minimal risk of harm to the human controller in cases of a crash, and second, they do less damage on crashing because they are relatively smaller in size (Sandbrook, 2015). Modern drones also come with more safety features such as obstacle avoidance systems and return to launch buttons on controllers than their predecessors. This notwithstanding, drones come with some heightened concerns of safety due mainly also to their pilotlessness (Finn \& Wright, 2012). How safe a particular drone system would be is influenced, to some extent, by the drone configuration. For instance, rotary winged drones tend to fall stone-like in cases of rotor failure while fixed-wing counterparts tend fall more gracefully. It is for this reason that drone licenses and flight permission are influenced by the type of drone.

Beyond safety is the ethical implications of research done using drones. The main issues of concern when discussing ethics in drone research are not markedly different from those that come up when using conventional research techniques like interviews, surveys, FGDs, among others. Indeed, the key issues of privacy, confidentiality, and consent are therefore still fundamental. The distinction of what constitutes the private sphere and public domain is critical. While drone data collection does not involve human test subjects per se, they often involve the observation of public places that humans are an intrinsic part of. In 
such contexts, it would be required that the data is recorded in a manner that individuals are not personally identifiable and if they were identifiable, disclosure of their identity outside of the research environment, would not place them at the risk of any harm (Resnik \& Elliott, 2019). Studies that do not meet these thresholds may be subject to institutional ethics reviews. On private property, however, studies will necessarily require consent from individuals to pass the ethics requirement. It is, for instance, not inconceivable that a drone captures an individual engaging in an illegal activity which would make them liable to criminal prosecution. The possibility of such accidental breaches of people's privacy means that drone operations over the private domain often requires researchers to obtain informed consent. Conversely, Sella-Villa (2020) argues that drones are primarily data collection devices whose impact on privacy is rather limited as they are not substantially different from other camera-equipped technology. From this perspective, if a photograph is taken, the platform used is largely irrelevant. This notwithstanding, certain unique characteristics and qualities of drones means that their use as data collection tools in the social sciences bring to the fore key ethical concerns.

Issues regarding ethics in drones research, like in many other fields, is not a straightforward one and are often riddled with inconsistencies and contradictions; what is private can quickly become public and viceversa. For example, can people have private moments in a public park and how does one draw the distinction? There remain many grey areas and no universality in principles regarding these requirements. For instance, what constitutes private information? While the airspace may reasonably be considered public space, would flying a drone over a farmer's field - in open view - require consent from them? What happens if they were growing marijuana on this field? Would institutional ethics review committees require researchers to gain informed consent for such drone operations? Moreover, obtaining informed consent from individuals in a drone's study can be a daunting task. Where, for instance, this involves an indefinite number of people in a village, it becomes impractical. In such a scenario, a community-wide forum prior to data collection becomes prudent. Through this, researchers could inform community members of what kind of information is to be collected and assure them of the protection of their privacy and confidentiality (Resnik \& Elliott, 2019). This could engender public trust and buy-in of drone projects. This is especially critical in resource conservation in the interest of long-term sustainability of projects long after researchers leave research communities (Sandbrook, 2015).

Despite their ubiquitous nature in the last few years, the capabilities of drones means that they are an excellent tool for surveillance since they capture data from a vantage perspective inaccessible to other technologies (Sella-Villa, 2020). There is, therefore, the need to be circumspect when applying them to data collection (Finn \& Wright, 2012). There is general agreement that researchers who employ drones to collect data ideally should submit their proposals to institutional review committees or some other oversight body for vetting to ensure compliance with ethical and regulatory standards (Resnik \& Elliott, 2019). While most drone studies, based on current ethical requirements, would qualify as exempt from such stringent reviews due to the minimal risk of harm to human subjects, researchers should nonetheless be aware of the possibility of ethical breaches that the collection of data in the public domain can occasion.

\section{Conclusions}

The last decade has seen a significant uptake in studies that use drones either as supporting tools or even main methods of data collection. Drones can have important roles to play in mixed methods, especially in the areas of natural resource conservation, agriculture, tourism, among others. In this paper, we have discussed the increasingly widespread application of drones as tools for research in the social sciences. Given the unique capabilities of drones, there is the need for adequate ethical considerations when using 
them in research. While they hold enormous potential in multiple fields of study, certain fields such as geography and archaeology are already more inclined to their application than others. In archaeology, drones have enabled hitherto unobserved remnants to become accessible to researchers. This has both positive and negative implications for heritage sites and indigenous populations. The application of drones in the fields of tourism studies and archaeology thus requires additional reflexivity to ensure that their use does not contribute to exploitation and looting of sites that were hitherto inaccessible. These considerations should fit into broader national guidelines and regulatory frameworks which should, in turn, be streamlined and be made less cumbersome to engender compliance. Certain barriers which in most countries are financial does not augur well for the adoption of the technology to reap the full benefits of their application.

Drones are already an inexorable part of society and so, spatial social scientists should be actively engaged with the use of the tool and be engaged in debates on the application of the technology as a tool in their increasingly dynamic toolbox. This will ensure that the benefits inherent in the use of drones are maximised without exacerbating possibilities of breaches in ethics. A key plank of this engagement is the teaching of specialised courses in drones in institutions of higher learning. Such a drone course will not only help students acquire the technical skills to operate drones but also help them explore ways in which the tool can be applied in their own research specialisations as well as enable them to engage critically with the ethical dilemmas inherent in its application in the social sciences. This latter discussion is critical as drones are becoming an integral tool in the toolbox of the social scientist as they become cheaper, safer, and more accessible. 


\section{References}

Adewopo, J., Peter, H., Mohammed, I., Craufurd, P., \& Vanlauwe, B. (2020). Can a Combination of UAV-Derived Vegetation Indices with Biophysical Variables Improve Yield Variability Assessment in Smallholder Farms? Agronomy, 10(12), 1934.

Alamouri, A., Lampert, A., \& Gerke, M. (2021). An Exploratory Investigation of UAS Regulations in Europe and the Impact on Effective Use and Economic Potential. Drones, 5(3), 63.

Ayamga, M., Tekinerdogan, B., \& Kassahun, A. (2021). Exploring the Challenges Posed by Regulations for the Use of Drones in Agriculture in the African Context. Land, 10(2), 164.

Barbedo, J. G. A. (2019). A Review on the Use of Unmanned Aerial Vehicles and Imaging Sensors for Monitoring and Assessing Plant Stresses. Drones, 3(2), 40. https://www.mdpi.com/2504446X/3/2/40

Beaver, J. T., Baldwin, R. W., Messinger, M., Newbolt, C. H., Ditchkoff, S. S., \& Silman, M. R. (2020). Evaluating the use of drones equipped with thermal sensors as an effective method for estimating wildlife. Wildlife Society Bulletin, 44(2), 434-443.

Birtchnell, T. (2017). Drones in human geography. In Handbook on geographies of technology. Edward Elgar Publishing.

Birtchnell, T., \& Gibson, C. (2015). Less talk more drone: Social research with UAVs. Journal of Geography in Higher Education, 39(1), 182-189.

Brown, A., Walsh, K., Fallu, D., Cucchiaro, S., \& Tarolli, P. (2021). European agricultural terraces and lynchets: from archaeological theory to heritage management. World Archaeology, 1-23.

Burke, C., Rashman, M., Wich, S., Symons, A., Theron, C., \& Longmore, S. (2019). Optimizing observing strategies for monitoring animals using drone-mounted thermal infrared cameras. International Journal of Remote Sensing, 40(2), 439-467.

Callow, J., May, S., \& Leopold, M. (2018). Drone photogrammetry and KMeans point cloud filtering to create high resolution topographic and inundation models of coastal sediment archives. Earth Surface Processes and Landforms, 43(12), 2603-2615.

Campana, S. (2017). Drones in archaeology. State-of-the-art and future perspectives. Archaeological Prospection, 24(4), 275-296.

Canal, D., \& Negro, J. J. (2018). Use of drones for research and conservation of birds of prey. In Birds of Prey (pp. 325-337). Springer.

Carrivick, J. L., \& Smith, M. W. (2019). Fluvial and aquatic applications of Structure from Motion photogrammetry and unmanned aerial vehicle/drone technology. Wiley Interdisciplinary Reviews: Water, 6(1), e1328.

Cucchiaro, S., Fallu, D. J., Zhao, P., Waddington, C., Cockcroft, D., Tarolli, P., \& Brown, A. G. (2020). SfM photogrammetry for GeoArchaeology. In Developments in Earth Surface Processes (Vol. 23, pp. 183-205). Elsevier.

Cummings, A. R., Cummings, G. R., Hamer, E., Moses, P., Norman, Z., Captain, V., Bento, R., \& Butler, K. (2017). Developing a UAV-based monitoring program with indigenous peoples. Journal of Unmanned Vehicle Systems, 5(4), 115-125.

Daponte, P., De Vito, L., Glielmo, L., Iannelli, L., Liuzza, D., Picariello, F., \& Silano, G. (2019). A review on the use of drones for precision agriculture. IOP Conference Series: Earth and Environmental Science, 275, 012022. https://doi.org/10.1088/1755-1315/275/1/012022

Dewi, R. (2016). Gaining recognition through participatory mapping? The role of adat land in the implementation of the Merauke Integrated Food and Energy Estate in Papua, Indonesia. ASEASAustrian Journal of South-East Asian Studies, 9(1), 87-105.

Finn, R. L., \& Wright, D. (2012). Unmanned aircraft systems: Surveillance, ethics and privacy in civil applications. Computer Law \& Security Review, 28(2), 184-194. https://doi.org/https://doi.org/10.1016/j.clsr.2012.01.005

Garrett, B., \& Anderson, K. (2018). Drone methodologies: Taking flight in human and physical geography. Transactions of the Institute of British Geographers, 43(3), 341-359. 
Glaw, X., Inder, K., Kable, A., \& Hazelton, M. (2017). Visual methodologies in qualitative research: Autophotography and photo elicitation applied to mental health research. International Journal of Qualitative Methods, 16, 1-8. https://doi.org/DOI: 10.1177/1609406917748215

Goodchild, M. F., \& Janelle, D. G. (2004). Spatially integrated social science. Oxford University Press.

Hall, O., Dahlin, S., Marstorp, H., Archila Bustos, M. F., Öborn, I., \& Jirström, M. (2018). Classification of Maize in Complex Smallholder Farming Systems Using UAV Imagery. Drones, 2(3), 22. http://www.mdpi.com/2504-446X/2/3/22

Harper, D. (2002). Talking about pictures: A case for photo elicitation AU - Harper, Douglas. Visual Studies, 17(1), 13-26. https://doi.org/10.1080/14725860220137345

Hay, B. (2016). Drone tourism: A study of the current and potential use of drones in hospitality and tourism. CAUTHE, 49-68.

Hodgson, M. E., \& Piovan, S. E. (2021). An indoor landscape for instruction of 3-D aerial drone imagery. Journal of Geography in Higher Education, 1-15. https://doi.org/10.1080/03098265.2021.1900084

Hodgson, M. E., \& Sella-Villa, D. (2021). State-level statutes governing unmanned aerial vehicle use in academic research in the United States. International Journal of Remote Sensing, 42(14), 53705399.

Holloway, P., Kenna, T., Linehan, D., O’Connor, R., Bradley, H., O’Mahony, B., \& Pinkham, R. (2021). Active learning using a smartphone app: analysing land use patterns in Cork City, Ireland. Journal of Geography in Higher Education, 45(1), 47-62.

Hunt, E. R., \& Daughtry, C. S. T. (2018). What good are unmanned aircraft systems for agricultural remote sensing and precision agriculture? International Journal of Remote Sensing, 39(15-16), 5345-5376. https://doi.org/10.1080/01431161.2017.1410300

Iost Filho, F. H., Heldens, W. B., Kong, Z., \& de Lange, E. S. (2019). Drones: Innovative Technology for Use in Precision Pest Management. Journal of Economic Entomology, 113(1), 1-25. https://doi.org/10.1093/jee/toz268

Jorz, V. (2019). Open Aerial Map, Drones and Archaeology: The implications of using drones to contribute and share aerial data on an open data repository University of Waterloo].

KCAA. (2020). Unmanned aircraft systems - Regulatory fees and charges. Nairobi: Kenya Civil Aviation Authority Retrieved from https://kcaa.or.ke/safety-\%26-security-oversight/unmanned-aircraftsystems

Ko, Y. D., \& Song, B. D. (2021). Application of UAVs for tourism security and safety. Asia Pacific Journal of Marketing and Logistics, ahead-of-print(ahead-of-print). https://doi.org/10.1108/APJML-07-2020-0476

Livermore, D. E., Moran, E., Rindfus, R., \& Stern, P. (Eds.). (1998). People and pixels: Linking remote sensing and social science. National Academies Press.

Marteau, B., Vericat, D., Gibbins, C., Batalla, R. J., \& Green, D. R. (2017). Application of Structurefrom-Motion photogrammetry to river restoration. Earth Surface Processes and Landforms, 42(3), 503-515.

Mathews, A. J., \& Wikle, T. A. (2019). GIS\&T pedagogies and instructional challenges in higher education: A survey of educators. Transactions in GIS, 23(5), 892-907.

Mol, L., \& Clarke, L. (2019). Integrating structure-from-motion photogrammetry into rock weathering field methodologies. Earth Surface Processes and Landforms, 44(13), 2671-2684.

Morrison, A., Tronstad, R., \& Martinussen, E. S. (2013). Design notes on a lonely drone. Digital Creativity, 24(1), 46-59.

Neocleous, M. (2013). Air power as police power. Environment and Planning D: Society and Space, 31(4), 578-593.

Otieno, B. (2021). KQ drone licence to cost pilots Sh 180,000. Business Daily Africa. https://www.businessdailyafrica.com/bd/corporate/companies/kq-drone-licence-to-cost-pilots$\underline{\operatorname{sh} 180-000-3482972}$ 
Paneque-Gálvez, J., Vargas-Ramírez, N., Napoletano, B. M., \& Cummings, A. (2017). Grassroots innovation using drones for indigenous mapping and monitoring. Land, 6(4), 86.

Piégay, H., Arnaud, F., Belletti, B., Bertrand, M., Bizzi, S., Carbonneau, P., Dufour, S., Liébault, F., Ruiz-Villanueva, V., \& Slater, L. (2020). Remotely sensed rivers in the Anthropocene: State of the art and prospects. Earth Surface Processes and Landforms, 45(1), 157-188.

Puri, V., Nayyar, A., \& Raja, L. (2017). Agriculture drones: A modern breakthrough in precision agriculture. Journal of Statistics and Management Systems, 20(4), 507-518.

Radjawali, I., \& Pye, O. (2017). Drones for justice: inclusive technology and river-related action research along the Kapuas. Geogr. Helv., 72(1), 17-27. https://doi.org/10.5194/gh-72-17-2017

Radjawali, I., Pye, O., \& Flitner, M. (2017). Recognition through reconnaissance? Using drones for counter-mapping in Indonesia. The Journal of Peasant Studies, 44(4), 817-833.

Resnik, D. B., \& Elliott, K. C. (2019). Using drones to study human beings: ethical and regulatory issues. Science and engineering ethics, 25(3), 707-718.

Rose, G. (2003). On the need to ask how, exactly, is geography "visual”? Antipode, 35(2), 212-221.

Rush, G. P., Clarke, L. E., Stone, M., \& Wood, M. J. (2018). Can drones count gulls? Minimal disturbance and semiautomated image processing with an unmanned aerial vehicle for colonynesting seabirds. Ecology and evolution, 8(24), 12322-12334.

Sandbrook, C. (2015). The social implications of using drones for biodiversity conservation. Ambio, 44(4), 636-647.

Sella-Villa, D. (2020). Drones and Data: A Limited Impact on Privacy. University of Richmond Law Review, Forthcoming.

Simic Milas, A., Cracknell, A. P., \& Warner, T. A. (2018). Drones-the third generation source of remote sensing data. International Journal of Remote Sensing, 39(21), 7125-7137. https://doi.org/10.1080/01431161.2018.1523832

Smith, D. A., Ibáñez, A., \& Herrera, F. (2017). The importance of context: Assessing the benefits and limitations of participatory mapping for empowering indigenous communities in the Comarca Ngäbe-Buglé, Panama. Cartographica: The International Journal for Geographic Information and Geovisualization, 52(1), 49-62.

Song, B. D., \& Ko, Y. D. (2017). Quantitative approaches for economic use of emerging technology in the tourism industry: unmanned aerial vehicle systems. Asia Pacific Journal of Tourism Research, 22(12), 1207-1220.

Stankov, U., Kennell, J., Morrison, A. M., \& Vujičić, M. D. (2019). The view from above: the relevance of shared aerial drone videos for destination marketing. Journal of Travel \& Tourism Marketing, 36(7), 808-822.

Stek, T. D. (2016). Drones over Mediterranean landscapes. The potential of small UAV's (drones) for site detection and heritage management in archaeological survey projects: A case study from Le Pianelle in the Tappino Valley, Molise (Italy). Journal of Cultural Heritage, 22, 1066-1071. https://doi.org/https://doi.org/10.1016/j.culher.2016.06.006

Tsiamis, N., Efthymiou, L., \& Tsagarakis, K. P. (2019). A comparative analysis of the legislation evolution for drone use in OECD countries. Drones, 3(4), 75.

Valle, R. G., \& Scarton, F. (2020). Drones improve effectiveness and reduce disturbance of censusing Common Redshanks Tringa totanus breeding on salt marshes. Ardea, 107(3), 275-282.

van Auken, P. M., Frisvoll, S. J., \& Stewart, S. I. (2010). Visualising community: using participant-driven photo-elicitation for research and application. Local Environment, 15(4), 373-388. https://doi.org/10.1080/13549831003677670

van der Merwe, D., Burchfield, D. R., Witt, T. D., Price, K. P., \& Sharda, A. (2020). Drones in agriculture. In Advances in Agronomy (Vol. 162). Academic Press. https://doi.org/https://doi.org/10.1016/bs.agron.2020.03.001

Vargas-Ramírez, N., \& Paneque-Gálvez, J. (2019). The global emergence of community drones (20122017). Drones, 3(4), 76. 
Vázquez-Tarrío, D., Borgniet, L., Liébault, F., \& Recking, A. (2017). Using UAS optical imagery and SfM photogrammetry to characterize the surface grain size of gravel bars in a braided river (Vénéon River, French Alps). Geomorphology, 285, 94-105.

Verma, A. K., \& Bourke, M. C. (2019). A method based on structure-from-motion photogrammetry to generate sub-millimetre-resolution digital elevation models for investigating rock breakdown features. Earth Surface Dynamics, 7(1), 45-66.

Wahab, I., Hall, O., \& Jirström, M. (2018). Remote Sensing of Yields: Application of UAV ImageryDerived NDVI for Estimating Maize Vigor and Yields in Complex Farming Systems in SubSaharan Africa. Drones, 2(3), 28. https://doi.org/https://doi.org/10.3390/drones2030028

Wahab, I., Jirström, M., \& Hall, O. (2020). An integrated approach to unravelling smallholder yield levels: The case of small family farms, Eastern Region, Ghana. Agriculture 2020, 10(206). https://doi.org/https://doi.org/10.3390/agriculture10060206

West, J. P., \& Bowman, J. S. (2016). The domestic use of drones: An ethical analysis of surveillance issues. Public Administration Review, 76(4), 649-659.

West, J. P., Klofstad, C. A., Uscinski, J. E., \& Connolly, J. M. (2019). Citizen support for domestic drone use and regulation. American Politics Research, 47(1), 119-151.

Williams, R. D., Tooth, S., \& Gibson, M. (2017). The sky is the limit: reconstructing physical geography from an aerial perspective. Journal of Geography in Higher Education, 41(1), 134-146.

Yonah, I. B., Mourice, S. K., Tumbo, S. D., Mbilinyi, B. P., \& Dempewolf, J. (2018). Unmanned aerial vehicle-based remote sensing in monitoring smallholder, heterogeneous crop fields in Tanzania. International Journal of Remote Sensing, 39(15-16), 5453-5471. 